\title{
Evaluating Direct-to-Consumer Marketing of Race-Based Pharmacogenomics: A Focus Group Study of Public Understandings of Applied Genomic Medication
}

\author{
BENJAMIN R. BATES \\ Ohio University, Athens, Ohio, USA \\ KRISTAN POIROT \\ University of South Carolina, Columbia, South Carolina, USA \\ TINA M. HARRIS \\ CELESTE M. CONDIT \\ University of Georgia, Athens, Georgia, USA

\section{PAUL J. ACHTER} \\ University of Richmond, Richmond, Virginia, USA

\begin{abstract}
Some medical providers have advocated applied genomics, including the use of genetically linked racial phenotypes in medical practice, raising fear that race-based medication will become justified. As with other emerging medical genetic technologies, pharmaceutical companies may advertise these treatments. Researchers fear that consumers will uncritically accept pharmaceutical messages and demand the product. In this exploratory study, we examined public reactions to advertisements for applied genomic medications. A focus group methodology was employed. Participants tended to resist the message and generated warrants for doing so, indicating critical reception of the messages. Message accepters also provided warrants. Warrants for resistance and acceptance differ between self-identified racial groups. Consumers, health care providers, and pharmaceutical corporations will benefit from a better understanding of direct-to-consumer advertisements as medical communication. Our study concludes that both advocates and opponents of direct-to-consumer advertisements should recognize that potential consumers of pharmacogenomics act as critical consumers of health advertising discourse.
\end{abstract}

This research was funded by the National Institutes of Health (HG02191-02) and a University of Georgia Distinguished Research Professorship. The authors acknowledge the contributions of Jennifer Bevan, Cynthia Dietz, Tasha Dubriwny, Tonia East, John Lynch, Nneka Ofulue, Roxanne Parrott, Amy Reeder, Kami Silk, and Candace Stargell to this article.

Address correspondence to Benjamin R. Bates, School of Communication Studies, Lasher Hall, Ohio University, Athens, OH 45710, USA. E-mail: batesb@ohio.edu 
On June 18, 2002, Senator Edward M. Kennedy prophesized on the future of American health care:

This century is still new, but it has already witnessed astonishing breakthroughs in medical research. Scientists have mapped the human genome-a task that once seemed impossible — and even inconceivable. Deciphering the code of life will have profound implications for preventing and curing disease. Treatments can be tailored to an individual's genetic signature. (Kennedy, 2002, p. 2)

Kennedy's vision of tailored medical treatment is not new. The prediction of an individualized treatment regimen accompanied by the best-known medical technology that would make such treatment possible is a dream as old as Hippocrates's Prognostic. And, as in Hippocrates's time, despite the best efforts of medical research, no medication is equally safe or efficacious for all patients.

Because there is not a single medication that is best for all patients, selecting the best medication for a given patient can present a challenge to medical providers. The sequencing of the human genome may help to resolve concern over which medication, if any, is best by providing better knowledge of disease and pharmaceutical mechanisms for individual patients (Roses, 2002). This process - pharmacogenetics-intends to provide the best drug for the patient. Yet, individual customization of medication in the near term is doubtful because patients are unlikely to be able to afford individualized medicines and because few physicians have the materials and machines required for genetic testing in their offices (Sander, 2000; Spear, Heath-Chiozzi, \& Huff, 2001).

As a compromise between pharmacogenetics for the individual and overall risk/benefit ratios from the entire population, some researchers have turned to applied medical genomicsthe evaluation of medications as they interact with genetically linked phenotypes-to resolve these concerns. That is, sexual, racial, or ethnic phenotypes, among others, are used as proxies for individual genotypes to allow interpatient generalization (Exner, Dries, Domanski, Cohn, 2001; Weber, 2001; Yancey et al., 2001). With the development of race-based genomic treatments, direct-to-consumer advertising for these products could and, likely, would become common (Hull \& Prasad, 2001a, 2001b). Since race-based genomics may have substantial consequences, both as a medical product and as an advertised product, the perception of these consequences by the public is an important aspect of the public understanding of these medications. Because the implications of the public understanding of applied genomics will become important to clinical medicine, we investigated interpretations of an advertisement for a fictional race-based genomic medication (see Figure 1) as a test case for patients' perceptions of these medications.

\section{Literature Review}

In the last 5 years there have been increasing calls for race-based assignment of pharmacogenomics (Risch, Burchard, Ziv, \& Tang, 2002; Wood, 2001). Although there is much

"If you are of African ancestry and you have a heart condition, the best drugs for treating you may be different than the drugs used for people of European ancestry. Compared to other medicines, Fairdil has been proven to be more effective for African-Americans in treating high blood pressure. Talk to your doctor to see if Fairdil is right for you."

FIGURE 1 Stimulus—Fictional advertisement for "Fairdil." 
dispute over the sufficiency of the match between genetics and socially designated race (Bamshad et al., 2003; Foster \& Sharp, 2002; Goodman, 2000; Graves, 2001; Halushka et al., 1999; Oppenheimer, 2001; Sankar \& Cho, 2003), race-based pharmacogenomics may provide a useful proxy for assignment of particular drugs that might be more effective among a majority of individuals of a socially identified racial group. Moreover, although the clinical utility of race-based pharmacogenomics has been questioned (Braun, 2002; Cooper, Kaufman, \& Ward, 2003; González-Burchard et al., 2003; Phimister, 2003; Schwartz, 2001; Wilson et al., 2001), there are already some uses of perceived race in medical diagnosis, prescription, and clinical trials of race-designated treatment assignment (Exner et al., 2001; Lee, Mountain, \& Koenig, 2001; McLeod, 2001; Satel, 2001).

In deciding on whether to implement race-based pharmacogenomics more formally and broadly, we must understand patient attitudes. Strong and salient attitudes about race and health may affect the uptake of race-based pharmacogenomics in pronounced ways. There is both a long history (Graves, 2001) and a clear contemporary condition (Smedley, Stith, \& Nelson, 2002) of disparity in treatment and health outcomes between African Americans and other American groups. This disparity can be traced to variety of factors including attitudes among physicians, attitudes among patients, and institutional forces (Smedley et al., 2002). All of these factors, and the resulting discrepancies, have generated substantial suspicion of the medical establishment by African Americans (CorbieSmith, Thomas, \& St. George, 2002).

An additional concern that accompanies pharmacogenetic research is that it will create the perception that medications are already individually tailored and that these medications are already available when pharmaceutical companies begin to advertise these medications. Hull and Prasad (2001a, 2001b) indicate that practitioners of applied genomics already have begun to advertise genetic testing on the basis of sex-linked probabilities for the development of genetically linked diseases. One of the difficulties with these advertisements is that they promote genetic distinctiveness between the sexes and use that as their primary appeal for a marketing claim, rather than focusing on the disease, its symptoms, and their treatments. Such claims are problematic in that they do not recognize that the mean variation in genotype among members of each sex is greater than the mean variation between the sexes (Condit, 1997). The relationships between sex and genetic difference and race and genetic difference are analogous. As such, the claims forwarded by Hull and Prasad (2001a, 2001b) that it is misleading, and occasionally downright incorrect, to emphasize genetic difference in medical advertising to make applied genomic claims about women may apply to emphasizing applied genomic claims about race. Moreover, because the manner in which a medication is presented can alter the consumer's perception of the use of the drug, the likelihood that they are a candidate for consuming it, and the risks and benefits associated with taking it, it is important to consider how the lay public responds to these advertisements (Davis, 2000; Gemperli, 2000).

Direct-to-consumer advertising may alter patient perceptions of the safety, efficacy, or appropriateness of a medication. More important, however, is the effect that viewing or hearing advertising for a prescription drug has on the likelihood that a person will consume the medication. Overall, there is circumstantial evidence that pharmaceutical advertising increases prescription sales, as spending on prescription drugs has risen as the number of direct-to-consumer advertisements has increased (Findlay, 2001, 2002; Rosenthal, Berndt, Donohue, Frank, \& Epstein, 2002). In addition, a number of studies have found that patients who are familiar with prescription drug advertisements are more likely to request more information about the drugs from their providers (Bell, Kravitz, \& Wilkes, 1999; Kravitz, 2000; Meade-D'Alisera, Merriweather, \& Wentland, 2001; Mintzes et al., 2002; Sumpradit, Fors, \& McCormick, 2002) and are more likely to ask 
that those drugs be prescribed (Huang, 2000; Kravitz, 2001; Zachry et al., 2002). Some studies laud the patient education and empowerment effects of direct-to-consumer advertising (Johnson \& Ramaprasad, 2000; Pines, 2000; Rothman, 2001), while others critique these advertisements for being misleading and for their potential to disrupt healthy patient-provider relationships (Bell, Wilkes, \& Kravitz, 2000; Davis, 2000; Woloshin, Schwartz, Tremmel, \& Welch, 2001).

Additionally, as genetic testing advertisements become more and more common, pharmaceutical companies may begin to advertise pharmacogenomic medications as well (Hull \& Prasad, 2001a, 2001b). Since race-based applied genomics already have shown promise for treating some conditions, it is also possible that pharmaceutical companies will make appeals based on race in their advertising campaigns. Exploring the effect that pharmacogenomic claims will have on the likelihood of a patient's decision to seek more information about a drug or to request a prescription for a drug may prove of interest. As such, we offer the following research question: How do potential consumers react to race-based appeals in direct-to-consumer marketing of applied pharmacogenomic medication?

Because the implications of the public understanding of race-based genomics may become important to clinical medicine, we investigated interpretations of an advertisement for a fictional medication (see Figure 1) as a test case for patients' perceptions.

\section{Design}

To access public understanding of race-based genomics, a focus group methodology was employed. In the Spring of 2002, we conducted 10 focus groups with 101 total participants. People with a lay understanding of genetics were recruited from urban (32), suburban (29), and rural (40) communities in Georgia. Focus groups were segmented first by the geographical location of the participant and then subdivided by the participant's selfidentified race. Five groups had persons self-identifying as "Black" or "African American," one group had persons self-identifying as "White" or "European American," and two groups had approximately equal numbers of African and European Americans. One group had persons self-identifying as multi racial and one group had persons self-identifying as Hispanic or Latino. Trained moderators were matched by self-identified race, with one integrated focus group being moderated by an African American female and the other moderated by a European American female. Sessions lasted about 2 hours.

Participants were recruited by nomination from a community advisory board in three areas. One of these areas was a large urban area, another was a regional hub that was primarily agricultural but is now in transition, and the last was a university town. The community advisory boards consisted of community leaders who advised the research team. The boards assisted the research tem in identifying and recruiting a representative sample of the community. The boards did not participate directly in the focus groups. Community advisory boards were first asked to discuss what constituted their community. Then they were asked to nominate individuals who would represent the breadth of perspectives in their community and who were not on the board. Those individuals were then telephoned by research team members and invited to participate if they did not selfidentify as "experts" in genetics. Participants were told which member of the community advisory board had nominated them and were offered $\$ 50$ to compensate them for transportation, childcare costs, and time.

Participants were 58 African Americans, 25 European Americans, 6 Hispanics, and 11 self-identified multiracial persons; 38 were female and 62 were male (1 participant declined to answer both questions). An overrepresentation of African Americans was 
recruited, as our fictional advertisement is designed to target African Americans. Participants ranged from 18 to 64 years of age $(M=32.8)$. Family income ranged from $\$ 10,000$ to $\$ 200,000$, with a median of $\$ 50,000$ (median income for Georgia is $\$ 36,372$ ). Educational levels ranged from less than high school $(2 \%)$ to a terminal degree $(1 \%)$. Most participants had a high school diploma (24\%), some college education $(38 \%)$, or had completed a bachelor's degree $(22 \%)$. The remainder had some graduate $(6 \%)$ or doctoral $(5 \%)$ education. All participants provided written informed consent, and appropriate institutional review boards approved the study.

Standard focus group procedures were followed (Morgan, 1993; Stewart \& Shamdasani, 1990). Moderators employed a common series of questions, which had been developed by the research team and then reviewed and revised by the three community advisory boards. Moderators were trained to include follow-up probes or to revise wordings in questions to seek full exploration of the issues by as many participants as possible. Participants viewed and heard the fictional advertisement (see Figure 1) and discussed it in small group settings. Audiotapes of the sessions were transcribed. These transcripts were then compared with the videotape and corrected as necessary. We did not correct transcripts for grammar or for formality in order to capture the oral nature of the discussion.

We analyzed the data using both quantitative and qualitative procedures. The quantitative procedures are designed simply to show the relative frequency of different themes within the data set, rather than to indicate the number of persons in the population who might hold any given attitude. To estimate the relative frequency of various themes, the data were divided into 906 statements; a statement consisted of the words uttered beginning when one participant began speaking until another participant spoke. A classification scheme (discussed in detail below) was developed based on readings of the transcripts. In other words, rather than using a preset measure, the research team developed categories based on emergent themes from the transcripts. As guided by our research question, we first developed categories for the overall type of response offered by a participant: belief in the message, a declaration of intent to investigate the message's claims, a decision to ignore the message, or a statement of resistance to the message. We then developed subcategories under each type of response to classify the reasons or means offered by the participant to believe, investigate, or resist the message and its claims. Two coders were then trained. They independently examined each transcript and coded participant statements into categories for each outcome measure. After coding, the coded responses were tabulated and the research team interpreted the findings.

\section{Results}

Results indicate that participants did not have a single interpretation of the advertisement. It is unsurprising that different participants would read the advertisement differently, as much extant research shows that audiences often perceive messages differently (Morley, 1980; Radway, 1986). Nonetheless, any differences in the overall responses to the message, as well as in the strategies adopted by participants in responses to the message, will have important implications for patient understanding of direct-to-consumer advertising of pharmacogenomic medicine and for physician prescription of pharmaceutical regimens.

To assess differences in the overall degrees of acceptance or suspicion of the advertisement, we developed four nominal categories: belief, ignore, investigation, and resistance. Belief statements were coded when the participants expressed outright acceptance of the Fairdil message or its claims. The participant's statement was coded as a decision to ignore the message if he or she claimed to disregard the message or its 
TABLE 1 Percentages and Distributions of General Responses to Message

\begin{tabular}{lccccc}
\hline & $\begin{array}{c}\text { African } \\
\text { Americans } \\
\%(N)\end{array}$ & $\begin{array}{c}\text { European } \\
\text { Americans } \\
\%(N)\end{array}$ & $\begin{array}{c}\text { Hispanic } \\
\text { Americans } \\
\%(N)\end{array}$ & $\begin{array}{c}\text { Multiracial } \\
\text { Americans } \\
\%(N)\end{array}$ & $\begin{array}{c}\text { Overall } \\
\%(N)\end{array}$ \\
\hline Believe message & $15(82)$ & $32(73)$ & $13(5)$ & $24(24)$ & $20(184)$ \\
Ignore message & $0(2)$ & $0(0)$ & $0(0)$ & $1(1)$ & $0(3)$ \\
Investigate message & $6(33)$ & $1(3)$ & $3(1)$ & $1(1)$ & $4(38)$ \\
Resist message & $48(259)$ & $43(99)$ & $63(25)$ & $40(40)$ & $47(423)$ \\
Nonresponsive & $30(161)$ & $23(53)$ & $23(9)$ & $35(35)$ & $28(258)$ \\
\hline
\end{tabular}

Note. $N=906$ statements, $k=.70, \chi^{2}=57.01$, d.f. $=12, p<.0001$.

claims. Investigation statements were coded if the participant indicated that she or he would consult with his or her physician or relevant medical literature to assess the Fairdil message or its claims. If the participant expressed clear and active suspicion about the Fairdil message, its claims, its implications, or all of these, the participant's response was coded as a resistance statement. Intercoder reliability was calculated to be Cohen's kappa (k) of .70, a level described by Landis and Koch (1977) as "substantial."

The dominant reaction to the fictional advertisement was suspicion about the message. Overall, a plurality of talk turns, regardless of a participant's self-reported race, expressed resistance to the message $(n=423)$. Despite the predominance of resistance to the message, a minority of statements revealed belief $(n=184)$ in the message and a desire to investigate the message's claims $(n=38)$. Overall, participant's statements are unlikely to indicate that the participant will ignore the message $(n=3)$. Participants responded within a continuum of reactions to the message. Differences between participant statements among ethnic groups were in degree, not kind (see Table 1). Overall, participants, statements are unlikely to indicate that the participant will ignore the message and their reasons for believing, investigating, and resisting the message are instructive. As such, the most interesting findings are revealed in a qualitative presentation of the various reasons for believing, investigating, and resisting the message.

\section{Strategies of Belief}

There is concern in the medical community that direct-to-consumer advertising will be believed without question. Studies that find that patients want to consume medication after viewing or hearing an advertisement often treat the consumer as irrational; she or he either does or does not want to consume the medication. Possible reasons for why a consumer would want to consume the medication are rarely asked. When treating belief statements, we categorized belief responses $(N=184)$ into nine nonmutually exclusive ways of believing the message $(k=.58$, moderate): that the medication offered health benefits $(n=29)$; that the scientific method was reliable $(n=11)$; that race-based research was needed $(n=18)$; that the Fairdil study would raise disease awareness $(n=57)$; that the message was inoffensive $(n=13)$; that media and medical sources could be trusted $(n=6)$; that social benefits other than health would come from the Fairdil message $(n=15)$; that races were genetically distinct, thus requiring different treatments $(n=36)$; and unqualified belief statements $(n=34)$.

The belief strategies employed are reported in Table 2. Overall, unqualified belief statements were not dominant, answering concerns that belief in advertised medicine 
TABLE 2 Percentage and Distribution of Belief Strategies Employed

\begin{tabular}{|c|c|c|c|c|c|}
\hline & $\begin{array}{l}\text { African } \\
\text { Americans } \\
\%(N)\end{array}$ & $\begin{array}{c}\text { European } \\
\text { Americans } \\
\%(N)\end{array}$ & $\begin{array}{l}\text { Hispanic } \\
\text { Americans } \\
\%(N)\end{array}$ & $\begin{array}{c}\text { Multiracial } \\
\text { Americans } \\
\%(N)\end{array}$ & $\begin{array}{l}\text { Overall } \\
\%(N)\end{array}$ \\
\hline $\begin{array}{l}\text { "Fairdil" offers health } \\
\text { benefits }\end{array}$ & $12(11)$ & $21(15)$ & $0(0)$ & $13(3)$ & $16(29)$ \\
\hline Trust in scientific method & $7(6)$ & $6(4)$ & $20(1)$ & $0(0)$ & $6(11)$ \\
\hline $\begin{array}{l}\text { Race-based research is } \\
\text { needed }\end{array}$ & $17(15)$ & $3(2)$ & $0(0)$ & $4(1)$ & $10(18)$ \\
\hline $\begin{array}{c}\text { "Fairdil" study raises } \\
\text { disease awareness }\end{array}$ & $19(17)$ & $34(24)$ & $40(2)$ & $58(14)$ & $31(57)$ \\
\hline $\begin{array}{l}\text { Participant is explicitly } \\
\text { not offended }\end{array}$ & $9(8)$ & $6(4)$ & $0(0)$ & $4(1)$ & $7(13)$ \\
\hline $\begin{array}{l}\text { Trust in media and } \\
\text { medical sources } \\
\text { expressed }\end{array}$ & $6(5)$ & $0(0)$ & $0(0)$ & $4(1)$ & $3(6)$ \\
\hline $\begin{array}{l}\text { "Fairdil" offers social } \\
\text { benefits other than } \\
\text { health }\end{array}$ & $9(8)$ & $8(6)$ & $0(0)$ & $4(1)$ & $8(15)$ \\
\hline $\begin{array}{l}\text { Races are believed to be } \\
\text { genetically distinct }\end{array}$ & $24(21)$ & $15(11)$ & $20(1)$ & $13(3)$ & $20(36)$ \\
\hline $\begin{array}{l}\text { Unqualified belief } \\
\text { statement }\end{array}$ & $21(19)$ & $15(11)$ & $20(1)$ & $13(3)$ & $18(34)$ \\
\hline
\end{tabular}

Note. $N=189$ statements, $k=.58, \chi^{2}=2254.87, d_{.} .=24, p<.0001$. Categories are not mutually exclusive; percentages do not add up to $100 \%$; distributions do not add up to 189 .

might be based on unreasoned acceptance, and thus be irrational. Participants generally had a reason for believing the message and its promotion of Fairdil when they chose to believe the message. The most common reasons for expressing belief in the message coincide with the dominant aims of the message. Participants' belief statements tend to emphasize the assumption that races are, indeed, genetically distinct, that a medication like "Fairdil" would offer health benefits to the person taking it for high blood pressure treatment, and that studying medications like "Fairdil" and reporting the results of those studies would help to raise disease awareness.

A closer reading of the participants' statements indicates that these themes commonly are united in participants' responses. For example P1010, an African American female, indicated that the Fairdil message would provide her with important health information and would allow her to seek the best treatment option:

It [high blood pressure] seems to be our disease, I'm not claiming that it is ours, there are few races that have high blood pressure, but basically it's a Black disease, so they would target us to come up with a drug to improve you know high blood pressure, so no, that [the Fairdil message] wouldn't offend me... that'll actually help me make an informed decision.

P301, a European American male, argued that the message was appropriate because it relied on actual genetic differences between ethnic groups and promoted a more effective medical option. He claimed, 
I think it's obvious that African Americans and the Black race are genetically different, so what? You know, it says, it may work better for you, genetically. But I wouldn't be offended by it and I don't think people should be.

Similarly, P105, a European American male, argued, "There's all different kinds of people, we have all different kinds of diseases. I think this sounds like good news for people of African descent with heart problems."

The participants also broadened their acceptance of the message beyond the best drug for African Americans alone. They indicated that if Fairdil presented the best treatment option for African Americans because there were actual genetic differences between ethnic groups, then other ethnic differences would promote drugs designed for other ethnic groups. That is, the most effective treatment option was taken to be a positive development from applied genomic research. P102, an African American female, stated that there were likely to be equivalent drugs and treatable conditions for different ethnic groups:

We're a member of the human race, but are we are different, in different things, in other ways. But not like our blood flows the same, and we eat the same, you know... . But we're different in some way, because we do have different diseases that are higher in the Black race and it might be in the White race and you all might have some in your race, than say Whites carry this or carry that more so than Black or Hispanic or whatever.

P504, a multiracial female agreed, holding that there were important health benefits that could be offered by treatments tailored to a person's observed ethnicity:

I don't feel like anything' cause I mean to know that specific races are prone to disease and that being established they want to further the improve health of these specific races.... I just think that knowing this will help improve the health of a particular race.

Likewise, P503, a multiracial male, pointed to the health benefits that would arise from the race-tailored medication and the awareness about disease susceptibility that advertisement for such drugs would raise:

The message would probably make me feel like I should be more aware of how my health is as far as I mean if they were to say, you know, "Look, we've got this pill for Asian people, Black people, White people, and look what it's going to do is cure your blood pressure or your migraines'cause you're prone to them." ...I need to go and find out do I have this problem. That's the way I would look at it.

These themes were repeated across the focus groups. Participant statements indicated that genetic difference, disease awareness, and a more effective treatment were seen as good reasons for accepting the message.

\section{Strategies of Investigation}

Some participants did not accept the message outright, choosing to conduct further investigation to see if they wanted to accept the claim. Although it is important to know 
that people intend to investigate a message further, the manner by which they investigate is also of interest. If many patients plan to ask their medical provider about a medication, providers can prepare for these opportunities for patient education. If patients intend to read other research about race-based medicine or intend to read the study that supports a specific race-based claim, current low levels of scientific literacy must be addressed. We recorded responses into four investigative strategies $(k=.84$, "almost perfect"): asking a physician $(n=9)$, examining race and medicine literature $(n=6)$, reading the "Fairdil Study" $(n=22)$, and a nonspecified declaration of intent to investigate the message $(n=1)$.

The declaration to investigate is relatively rare (see Table 3). The declaration of intent to investigate appears more often in statements from African Americans $(n=33)$ than it does in statements from members of other ethnic groups $(n=5)$. The dominant mode of investigation is to seek more information about the original Fairdil study. As a message designed for African American audiences, however, it is unsurprising that African Americans should express more interest in knowing more about the medication advertised than members of other ethnic groups.

A majority of African Americans who stated an intent to investigate the message indicated that they wanted to read the Fairdil study and evaluate how well it supported the claim that there are differential racial responses to heart disease medication. Some of these responses were receptive to the advertisement's claims, as revealed in the response of P411, an African American male, who stated,

I would need more detail....How do they know? What kind of research was done? You know? Saying that African Americans ...more. What kind of studies? What kind of R\&D? I'm thinking about research. So, yeah, it's pretty vague to me.

Others, however, expressed fear that drug companies would just assume that they would not be interested in the research. P904, an African American female stated:

This message is kind of, I should say, insulting your intelligence. They've gone putting all this little basic stuff out not saying who did the study and what African Americans, what population, where you got them from? They're not putting no solid facts in there and they're just taking for granted, "Oh, we're going to put this out here and they're going to hear it. This is best for African Americans so African Americans are going to go out and buy it, because we say it's the best for them." I think it's just insulting our intelligence, how much they

TABLE 3 Percentage and Distribution of Investigative Strategies Employed

\begin{tabular}{lccrrr}
\hline & $\begin{array}{c}\text { African } \\
\text { Americans } \\
\%(N)\end{array}$ & $\begin{array}{c}\text { European } \\
\text { Americans } \\
\%(N)\end{array}$ & $\begin{array}{c}\text { Hispanic } \\
\text { Americans } \\
\%(N)\end{array}$ & $\begin{array}{c}\text { Multiracial } \\
\text { Americans } \\
\%(N)\end{array}$ & $\begin{array}{c}\text { Overall } \\
\%(N)\end{array}$ \\
\hline Ask provider & $18(6)$ & $67(2)$ & $0(0)$ & $100(1)$ & $24(9)$ \\
Examine other research & $18(6)$ & $0(0)$ & $0(0)$ & $0(0)$ & $16(6)$ \\
Read the "Fairdil study" & $60(20)$ & $33(1)$ & $100(1)$ & $0(0)$ & $58(22)$ \\
Self-experiment & $3(1)$ & $0(0)$ & $0(0)$ & $0(0)$ & $3(1)$ \\
\hline
\end{tabular}

Note. $N=38$ statements, $k=.84, \chi^{2}=25.17$, d.f. $=9, p<.003$. 
just know for a fact that we wouldn't go out and research or we wouldn't want to know any more than that.

Smaller portions of the African Americans intending to investigate the message indicated that they will ask their physician about Fairdil or that they would read other studies that examine the effect of race on response to medication. For example, P1010, an African American female, said that people should "at least seek more information about it. And you go to your doctor and ask him, you know, you have my history, you know everything about me, am I a good candidate for this drug?" These strategies of information seeking indicate that some participants want to know more about the basis of the Fairdil message before evaluating its claims.

\section{Strategies of Resistance}

A plurality of participants overall and within ethnic groups indicated that they would pursue a resistance strategy in dealing with the Fairdil message. As with belief strategies, it is not enough to know if a patient intends to resist a pharmacogenetic message. We are also interested in the rationale he or she provides for resisting the message. If medical providers wish patients to accept prescriptions or regimens that initially are rejected by lay people, they need to understand the basis for these rejections. If the bases are reasonable, then the medical provider can engage the grounds of resistance specifically. Irrational, or even paranoid, resistance strategies may present much greater barriers when a provider determines that a particular medication will lead to significantly better health outcomes for the patient. We recorded resistance strategies into 13 nonmutually exclusive types $(k=.66$, "substantial"): a claim to be offended $(n=8)$; a claim that behavioral factors outweighed genetic factors $(n=22)$; a decision to use alternative, not allopathic, medicine $(n=16)$; claims about pharmaceutical company conspiracies $(n=65)$; claims that races are not genetically distinct $(n=32)$; claims that individual difference, not racial differences, were what mattered $(n=36)$; worries about racial discrimination $(n=78)$; worries about genetic discrimination $(n=18)$; worries about discrimination in general $(n=70)$; claims about racist conspiracies such as genocide $(n=24)$; concerns about Fairdil's toxicity $(n=15)$; and unqualified resistance statements $(n=81)$.

Apparent differences emerged between ethnic groups in terms of specific strategies of resistance (see Table 4). African Americans' statements indicated the most diverse repertoire of strategies. For all racial groups, possible discriminatory effects from pharmacogenomic research are a substantial concern. A fear of discrimination, whether based on race, genetics, or unspecified, is common.

African American participants were most likely to see extreme discriminatory impacts, such as genocide, as the result of applied genomic research. For example, P603, an African American male, stated:

After the Tuskegee experiment, I just about run another way. You know, I'm pretty-I'm real skeptical about medicine anyway ... I'd stay away from medicines because I'm just convinced that, you know, when it comes down to AIDS and stuff like that, you know, I'm convinced that it was meant to, you know, for some reason. It's an old rumor and it never really substantiated, you know, conspiracy theory. But I just feel like, you know, this government and this world don't really mean Black people no good, you know, and, consequently, you know, I just don't put anything past them. I know in South Africa, you know, they've broken out Apartheid and they found out that they had all types of 
TABLE 4 Percentage and Distribution of Resistance Strategies Employed

\begin{tabular}{|c|c|c|c|c|c|}
\hline & $\begin{array}{l}\text { African } \\
\text { Americans } \\
\%(N)\end{array}$ & $\begin{array}{c}\text { European } \\
\text { Americans } \\
\%(N)\end{array}$ & $\begin{array}{l}\text { Hispanic } \\
\text { Americans } \\
\%(N)\end{array}$ & $\begin{array}{c}\text { Multiracial } \\
\text { Americans } \\
\%(N)\end{array}$ & $\begin{array}{l}\text { Overall } \\
\%(N)\end{array}$ \\
\hline Claim to be offended & $1(3)$ & $2(2)$ & $0(0)$ & $8(3)$ & $2(8)$ \\
\hline $\begin{array}{l}\text { Behavior is heart disease } \\
\text { factor, not genetics }\end{array}$ & $6(16)$ & $4(4)$ & $4(1)$ & $3(1)$ & $5(22)$ \\
\hline $\begin{array}{l}\text { Participant chooses } \\
\text { alternative medicine }\end{array}$ & $6(16)$ & $0(0)$ & $0(0)$ & $0(0)$ & $4(16)$ \\
\hline $\begin{array}{l}\text { Pharmaceutical conspiracy } \\
\text { indicated }\end{array}$ & $8(21)$ & $41(41)$ & $12(3)$ & $0(0)$ & $15(65)$ \\
\hline $\begin{array}{l}\text { Races claimed to be not } \\
\text { genetically distinct }\end{array}$ & $5(13)$ & $4(4)$ & $12(3)$ & $30(12)$ & $8(32)$ \\
\hline $\begin{array}{l}\text { Individual drug response } \\
\text { is central factor, not } \\
\text { racial response }\end{array}$ & $11(27)$ & $5(5)$ & $8(2)$ & $13(2)$ & $9(36)$ \\
\hline $\begin{array}{l}\text { "Fairdil" study risks } \\
\text { racial discrimination }\end{array}$ & $17(43)$ & $22(22)$ & $28(7)$ & $15(6)$ & $18(78)$ \\
\hline $\begin{array}{l}\text { "Fairdil" study risks } \\
\text { genetic discrimination }\end{array}$ & $6(16)$ & $1(1)$ & $0(0)$ & $0(0)$ & $4(18)$ \\
\hline $\begin{array}{l}\text { "Fairdil" study risks } \\
\text { unspecified } \\
\text { discrimination }\end{array}$ & $17(43)$ & $15(15)$ & $12(3)$ & $23(9)$ & $8(70)$ \\
\hline $\begin{array}{l}\text { Racist conspiracy } \\
\text { indicated }\end{array}$ & $8(22)$ & $1(1)$ & $4(1)$ & $0(0)$ & $6(24)$ \\
\hline $\begin{array}{l}\text { "Fairdil" will have toxic } \\
\text { side effects }\end{array}$ & $4(9)$ & $6(6)$ & $0(0)$ & $0(0)$ & $4(15)$ \\
\hline $\begin{array}{l}\text { Unqualified resistance } \\
\text { statement }\end{array}$ & $19(49)$ & $17(17)$ & $28(7)$ & $20(8)$ & $19(81)$ \\
\hline
\end{tabular}

Note. $N=418$ statements, $k=.66, \chi^{2}=183.69$, d.f. $=33, p<.0001$. Categories are not mutually exclusive; percentages do not add up to $100 \%$; distributions do not add up to 418 .

programs going on to- - similar to the Nazis. You know, they were doing to Jews, but they would try and develop and design for Black people and that was in the New York Times late last year.

Additionally, P608, an African American female, interpreted claims about Fairdil through her knowledge of past medical discrimination. She stated,

I mean, our government's history in this country, I would seriously have to question, "What are they trying to do to us now?" I really would. And what is the drug? Is it going to kill more of us before we're 55? I mean, what's going on and historically.... So I couldn't-I don't know if I could trust something like that.

Although these fears are extreme, they are not uncharacteristic of the African American respondents' statements. In fact, they represent about $8 \%$ of African American responses. 
More common is the fear of general, everyday kinds of discrimination that messages like the Fairdil message may promote.

When all forms of discrimination are combined, nearly half of all participants' statements point to a fear of some kind of discrimination as the reason the Fairdil message should be resisted. P808, a European American female, stated, "I think people ...who have tendency to be racist will look for whatever reasons like if it's something big and out in the open of this race, I mean it's just going to be another thing they are going to tag on to... discriminate against ... over people about." As such, she felt that racists would simply convert the message about Fairdil into another reason to dislike persons of color. Support for claims of discrimination also often rested in previous group associations with diseases. For instance, P512, a multiracial female, argued:

I think that it would be the same thing as when the AIDS epidemic came into the media and they labeled it as a gay man's disease or you know whatever some people wanted to put it on a race and it's like there's certain diseases like STDs [sexually transmitted diseases] and like you know whatever it's not necessarily a race it's in action that you get it. You know and I think it will happen again how that whole thing that they fight so hard to say it's not a gay man's disease, straight people can get it too and actually you know the easiest way to get it is heterosexual sex and that you know so it doesn't matter and I think it will happen again them having to fight to, like, curb discrimination.

Through the analogy to homosexuals and AIDS, P512 clearly explained her fear. People would hear the Fairdil messages and assume that African Americans were the carrier of a disease based simply on a demographic grouping. Moreover, P512 indicated that the disease would become essentialized to one demographic group and create a false sense of immunity in people who were not part of that population.

Regardless of self-identified race, statements from African Americans (48\%), European Americans (49\%), Hispanic Americans (44\%), and multiracial Americans (48\%) all indicated fear that the message would lead to some sort of discrimination. P904, an African American female, revealed her fears when she explained that the Fairdil message could promote discrimination in other societal arenas:

It's like, 'Well, it say African American, so I guess all of them have it.' ... They hear something, "African American are more prone to this disease." ... And once you start digging up all that stuff, learn about stuff they don't know that possibly they may get it. They may not. Then they may discriminate, because well there's this good possibility that they may die from this, then my company's going to have to pay money.

P207, a Hispanic American male, made a similar comment:

To me this is going to be creating more and more segregation, the whole issue of discrimination is ... most White folks will accept a Latino more than they'll ever accept an African American,... even though they've been here longer... I think it's sick. I mean, the African American community already has problems, they already have issues dealing with, um, even in this local community, when I say, "acceptance," I think a singling them out even more, and I think it's going to create even more discrimination towards them. 
Overall, the fear of discrimination, both in medical treatment and in general society, is a substantial concern identified by our participants.

In other resistance strategies, there are other differences. European Americans appeared most likely to resist the Fairdil message on the grounds that it is part of a pharmaceutical plot wherein providers and drug companies create advertising simply to sell a product, not because it is actually better for the patient than are other products. Although P107, a European American male, said, "I think it's just big drug companies target marketing," others articulated concerns about pharmaceutical conspiracies involving physicians. P408, a European American female, explained:

\begin{abstract}
All my family's in medicine, so I've seen the other side of it too. And they come home every day and tell me stories, and every story they say-From an ad like this, she will have 50 people come in and say, "I want this drug. I don't care what it does. It's marketed and I want this drug." So in that aspect, I know it does target people and the ad does work... I don't see it as offensive. I just see it as a marketing ploy like you guys were talking about. It's for money. There's this one drug. It's all in the pocket of the doctors who have interest in it and it's in their interest to sell it. They too in most cases. So that's how I look at it, it's kickbacks. But I don't think offended is the right word and I don't want to sound bad either. I don't know how to phrase it.
\end{abstract}

In short, although all groups are aware of the potential for other harmful implications of the message, European Americans tend to focus more on pharmaceutical economic structures and other groups are likely to emphasize that skin color (a phenotypic difference) does not necessarily mean that a medication is actually better on the genotypic level.

\title{
Discussion
}

As the results indicate, there was no single interpretation of the message, but participants are more likely to employ a resistance strategy than any other type of use strategy. Since there is a spectrum of suspicion across all participants, what becomes interesting are the apparent race-based differences in the strategies used to react to the message, not the general type of reaction. It appears that self-identified race plays a role in the particular strategies of resistance, investigation, and belief adopted. The historical and social context in which different ethnic communities come to understand pharmacogenetic messages may play a role in the public understanding of genetic medicine, a condition that may significantly constrain clinical pharmacogenetics. Nonetheless, shared understanding of the possible benefits of applied genomics may provide a common platform for the acceptance of pharmacogenomic medication.

Although a plurality of participant responses indicate that consumers will resist the message, a substantial minority states a belief in the message. The Fairdil message indicates that African Americans are different from other races and may need a particular medication for a common disease. The three predominant belief strategies - that races are genetically distinct, that Fairdil can offer health benefits, and that Fairdil may raise disease awareness - are consistent with the message strategy. Participants, when most accepting of the message, relied on the message's encoded justifications, a finding that agrees with much recent research (see Davis, 2000; Gemperli, 2000; Huang, 2000, for example). As a device to inform consumers and to promote the consumption of medication, advertisements like that of Fairdil can inform some consumers in a way that is 
likely to encourage them to accept and consume the medication. Advertisements for pharmacogenomic medications may alter potential patients' perceptions that a medicine has greater efficacy for their population and, thus, could increase the likelihood that the patient will request information or a prescription.

Beyond accepting Fairdil because it might be more effective, a substantial minority of African Americans indicated that they believed the message because Fairdil could provide other social benefits. This suggests a symbolic dimension of strategies of belief. As African Americans historically have faced medical discrimination, they may perceive a drug designed for them as indicative of a changing medical environment. As one African American female (P804) put it, "At least they are taking us into consideration." We gain support for this symbolic benefit when non-African Americans suggest that a message targeted toward them would be accepted because it would indicate a message for their own self-identified race. For example, P207 claims, "If it said Latino here, I'd be checking myself out—absolutely." Likewise, P801, a European American male, said that if the message was for European Americans, he "would just feel good that someone came and found a medicine that would help [him]." Thus, being the message's subject may indicate symbolically that one's own health concerns are worthy of attention. As the majority of the responses do indicate that there will be material health benefits, these benefits, along with the symbolic benefits suggested, indicate topoi of understanding genetics and medicine prompted by the message itself and larger cultural factors. Such understanding can help health care professionals to facilitate acceptance of pharmacogenetic medications.

Despite these opportunities for formulating acceptance, the symbolic benefits of drugs like Fairdil were outweighed by concerns about both the material and symbolic consequences of applied genomics. These potential consequences of Fairdil appear in the participants' resistance strategies and should be a concern for health care professionals. Specifically, the participants were likely to focus on racial discrimination and, to a lesser degree, genetic discrimination. Just as applied genomics creates the opportunity for physicians to practice medicine based on observed race (Smedley et al., 2002), our participants indicate that pharmacogenomics messages will create genetic warrants for the practice of phenotype classification. This classification on observed skin color differences creates, in the participants' views, possibilities for racist medical and social practice.

Although all groups fear the possible racist use of applied genomics and messages about them, the degree of this risk varies. Unsurprisingly, African Americans were most likely to fear a racist conspiracy. Indeed, the reference to the Tuskegee experiments in these discussions shows how well-known instances of racist medical discrimination can influence the interpretation of race-based applied genomics. When similar symbolism is employed in belief strategies, Tuskegee and personal experiences become synecdochic of the dangers of race-based medicine. Although the Fairdil message was based on genetic findings, the deployment of the message within media representations, reports, and physician practice always refers back to race via skin color, or phenotypic expression. And, as race-based genomics emphasize the phenotype not the genotype, such emphasis does not escape the participants. For the participants, race-based genomics becomes another way to practice race-based medicine, not the proper deployment of recent medical findings. Despite efforts to introduce the benefits of genetically tailored medicine, in this species of applied genomics race remains the concern, not genetics.

The potential problems of discrimination did not escape any of the groups. A substantial number of European Americans, a group less likely to have faced medical discrimination than any other, mentioned the possibility of racial discrimination as a 
reason to resist the message. Indeed, the sheer number of racial discrimination responses indicates both an awareness of and fear of race-based medical discrimination. European Americans, however, were more likely to indicate a fear of pharmaceutical conspiracy than was any other group. Also, European Americans were nearly as likely to emphasize economic power as they are were to mention racial privilege. That is, European Americans emphasize an economic discrimination/conspiracy, whereas other groups emphasize racial discrimination/conspiracy. European Americans are more likely to face economic discrimination than racial discrimination, and as such are more likely to employ a relevant fear as their resistance strategy. Similarly, groups more likely to face racial discrimination employed it as the relevant interpretive frame. These findings signal that because of a person's particular race, certain kinds of discrimination may be more relevant to their resistance to pharmacogenomic messages. Health care providers should consider such factors in recommending treatments, as they suggest that applied genomics cannot escape the perceived consequences of race-based medicine.

The warrants offered by the participants for resisting or accepting the Fairdil message accord well with the warrants offered by critics and advocates of race-based pharmocogenetics. Race-based genomics also may distract researchers from genotypic factors, lessening pharmacogenetic advantages for individualized patient treatment (Schwartz, 2001; Wood, 2001). Both the professional and lay communities are concerned that physicians may use the color of a patient's skin to determine the treatment prescribed, rather than to consider the actual individual differences that pharmacogenomics is designed to identify. The mean variation of genetic differences within ethnic groups is three to five times greater than the mean variation of differences between ethnic groups (Nebert \& Bingham, 2001). The importance of individual differentiation in genotype remains significant. Therein lies the potential problem of race-based genomics. Under the guise of providing an individually tailored medication, race-based genomics relies on categories that may not be accurate predictors of genotype. The focus on race also may naturalize and extend beliefs of genetic differences among races (Oberlin, 2001; Schwartz, 2001), a concern noted by our participants. As such, racebased genomics risks, at the very least, minimizing any potential medical benefit of pharmocogenomic medication and improperly emphasizing an identification of genetically distinct racial categories. Nonetheless, applied genomics bears a pragmatic impact on rational drug design at the laboratory phase (Weber, 2001) and has evinced some clinical benefits (Exner et al., 2001; Yancey et al., 2001). Applied genomics, therefore, can justify race-based medicine and has the potential benefits and perils that attend its practice.

The need for health care providers to consider historical and social factors in recommending treatment options is salient particularly when potential patients adopt a strategy of investigation. Although the greater tendency for African Americans to investigate the message may be an artifact of group communication dynamics, rather than an ethnic divide, the repetition of this theme across focus groups may indicate that African Americans have a greater interest in claims made about African American health issues than do members of other ethnic groups. Explanations for why an applied genomic medication is not simply a race-based treatment need to be readily available and clearly explained to the consumer. Although many participants indicated that they would ask a physician about Fairdil, more indicated that they would do research on their own. Although this finding suggests that making research data on particular drugs available to the public would be helpful, patients doing research "on their own" raises questions of scientific literacy. Health educators may need to address patients' scientific literacy or illiteracy and emphasize their roles as learned intermediaries. 


\section{Conclusions}

Pharmacogenetic research holds great promise for individual treatment regimens. As the costs of genetic testing decline and health care providers become more comfortable with the practice of pharmacogenomics, the potential for tailored treatment becomes greater. Actual pharmacogenetic practice, though, is a long way off. Senator Kennedy's vision of medical practice may come to fruition, or it may remain a vision of hope like Hippocrates's dream. Applied genomics may offer some clinical benefits. As a common practice, however, race-based genomics may naturalize phenotypic distinctions as differences that matter. Because of this naturalization, some practitioners fear that applied pharmacogenomics may sustain or encourage racism in other arenas. Any benefit that applied genomics has in the lab may be outweighed by its practice in the clinic and in society as a topic of invention by advocates of fundamental racial differences.

This study also has implications for our understanding of direct-to-consumer advertising. Studies of direct-to-consumer advertisements have found that consumers who have seen an advertisement for a medication are more likely to request a medication than those who have not seen an advertisement. We did not find blithe acceptance of advertisements. Instead, we find that many potential consumers read the direct-toconsumer advertisements of applied genomic medications through a critical lens. They are most likely to resist messages that their experiences suggest are problematic and are able to forward reasons for not accepting the medication. Even when the potential patient believes the advertisement, the patient does so with a reason. This more complex reading of direct-to-consumer-advertisements provides a better understanding than does a simple direct correlation between advertisement viewing and prescription requests. By examining warrants for accepting and dismissing a message, we can better investigate directto-consumer advertisements and understand the use and function of these advertisements for the potential patient population.

It is important to note that our findings are exploratory in nature, and, as such, additional studies will be needed to explore the generalizability of this data. Not only do we need additional research on representative population samples, but also research is needed with a variety of messages. Because focus groups are prone to group dynamics, other methodologies such as individual surveys also may be useful to test the robustness of these findings, especially of those findings comparing responses by racial group. Nonetheless, because there are significant social impacts to applied genomic research and its expression in broader society, the way that applied genomic findings are made known to the public must be carefully framed. Our findings suggest that responses to pharmaceutical direct-to-consumer advertising may be based on a variety of reason-based resources, not simple acceptance, and, furthermore, that race-based messages within these advertisements are likely to be resisted. Health care providers, as learned intermediaries, must be prepared to discuss these implications as a mode of provider intervention and patient education. Last, as these messages begin to become more prevalent, communication researchers are obligated to study these messages and their social impact on the public understanding of genetic science and genetic medicine.

\section{References}

Bamshad, M. J., Wooding, S., Watkins, W. S., Ostler, C. T., Batzer, M. A., \& Jorde, L. B. (2003). Human population genetic structure and inference of group membership. American Journal of Human Genetics, 72, 578-589.

Bell, R. A., Kravitz, R. L., \& Wilkes, M. S. (1999). Direct-to-consumer prescription drug advertising and the public. Journal of General Internal Medicine, 14, 705-706. 
Bell, R. A., Wilkes, M. S., \& Kravitz, R. L. (2000). The educational value of consumer-targeted prescription drug print advertising. Journal of Family Practice, 49, 1092-1098.

Braun, L. (2002). Race, ethnicity, and health: Can genetics explain disparities? Perspectives in Biology and Medicine, 45, 159-174.

Condit, C. M. (1997). In praise of eloquent diversity: Gender and rhetoric as public persuasion. Women's Studies in Communication, 20, 91-116.

Cooper, R. S., Kaufman, J. S., \& Ward, R. (2003). Race and genomics. New England Journal of Medicine, 348, 1166-1170.

Corbie-Smith, G., Thomas, S. B., \& St. George, M. M. (2002). Distrust, race, and research. Archives of Internal Medicine, 162, 2458-2463.

Davis, J. J. (2000). Riskier than we think? The relationship between risk statement completeness and perceptions of direct to consumer advertised prescription drugs. Journal of Health Communication, 5, 349-369.

Exner, D. V., Dries, D. L., Domanski, M. J., \& Cohn, J. N. (2001). Lesser response to angiotensinconverting-enzyme inhibitor therapy in black as compared with white patients with left ventricular dysfunction. New England Journal of Medicine, 344, 1351-1357.

Findlay, S. (2001). Direct-to-consumer promotion of prescription drugs: Economic implications for patients, payers, and providers. Pharmacoeconomics, 19, 109-119.

Findlay, S. (2002). Do ads really drive pharmaceutical sales? The true effects of DTC advertising remain a mystery. Marketing Health Services, 22, 20-25.

Foster, M. W. \& Sharp, R. R. (2002). Race, ethnicity, and genomics: Social classifications as proxies of biological heterogeneity. Genome Research, 12, 844-850.

Gemperli, M. P. (2000). Rethinking the role of the learned intermediary: The effects of directto-consumer advertising on litigation. MSJAMA, 284, 2241.

González-Burchard, E., Ziv, E., Coyle, N. Gomez, S. L., Tang, H., Karter, A. J., Mountain, J. L., Pérez-Stable, E. J., Sheppard, D., \& Risch, N. (2003). The importance of race and ethnic background in biomedical research and clinical practice. New England Journal of Medicine, $348,1170-1175$.

Goodman, A. H. (2000). Why genes don't count (for racial differences in health). American Journal of Public Health, 90, 1699-1702.

Graves, J. L. (2001). The emperor's new clothes: Biological theories of race at the millennium. New Brunswick, NJ: Rutgers University Press.

Halushka, M. K., Fan, J. B., Bentley, K., Hsie, L., Shen, N., Weder, A., Cooper, R., Lipshutz, R., \& Chakravarti, A. (1999). Patterns of single-nucleotide polymorphisms in candidate genes for blood-pressure homeostasis. Nature Genetics, 22, 239-247.

Huang, A. J. (2000). The rise of direct-to-consumer advertising of prescription drugs in the United States. MSJAMA, 284, 2240.

Hull, S. C. \& Prasad, K. (2001a). Reading between the lines: Direct-to-consumer advertising of genetic testing in the USA. Reproductive Health Matters, 9(18), 44-48.

Hull, S. C. \& Prasad, K. (2001b). Reading between the lines: Direct-to-consumer advertising of genetic testing. Hastings Center Report, 31(3), 33-35.

Johnson, G. L. \& Ramaprasad, A. (2000). Patient-physician relationships in the information age. Marketing Health Services, 20, 20-27.

Kennedy, E. M. (2002, June 18). America's forgotten health care agenda: A call for action. Retrieved September 2, 2002, from http://kennedy.senate.gov/npcspeech061802.pdf

Kravitz, R. L. (2000). Direct-to-consumer advertising of prescription drugs: Implications for the patient-physician relationship. MSJAMA, 284, 2244.

Kravitz, R. L. (2001). Direct-to-consumer advertising of prescription drugs. Western Journal of Medicine, 173, 221-222.

Landis, J. R. \& Koch, G. G. (1977). The measurement of observer agreement for categorical data. Biometrics, 33, 159-174.

Lee, S. S., Mountain, J., \& Koenig, B A. (2001). The meanings of "race" in the new genomics: Implications for health disparities research. Yale Journal of Health Policy, Law, \& Ethics, 1, $33-75$. 
McLeod, H. L. (2001). Pharmacogenomics: More than skin deep. Nature Genetics, 29, 247-48.

Meade-D'Alisera, P., Merriweather, T., \& Wentland, M. (2001). Impact of commercial marketing on patient demand. Urological Nursing, 21, 406-27, 410.

Mintzes, B., Barer, M. L., Kravitz, R. L., Kazanjian, A., Bassett, K., Lexchin, J., Evans, R. G., Pan, R., \& Marion, S. A. (2002). Influence of direct to consumer pharmaceutical advertising and patients requests on prescribing decisions: Two site cross sectional survey. British Medical Journal, 324, 278-279.

Morgan, D. L, (ed.) (1993). Successful focus groups: Advancing the state of the art. Newbury Park, CA: Sage.

Morley, D. (1980). The "nationwide" audience: Structure and decoding. London: British Film Institute.

Nebert D.W. \& Bingham, E. (2001). Pharmacogenomics: Out of the lab and into the community. Trends in Biotechnology, 19, 519-523.

Oberlin, C. (2001). "Racial": Is it an appropriate word for a scientific publication? Plastic and Reconstructive Surgery, 108, 801.

Oppenheimer, G. M. (2001). Paradigm lost: Race, ethnicity, and the search for a new population taxonomy. American Journal of Public Health, 91, 1049-1055.

Phimister, E. G. (2003). Medicine and the racial divide. New England Journal of Medicine, 348, 1081-1082.

Pines, W. L. (2000). Direct-to-consumer advertising. Annals of Pharmacotherapy, 34, 1341-1344.

Radway, J. (1986). Identifying ideological seams: Mass culture, analytical methods, and political practice. Communication, 9, 93-123.

Risch, N., Burchard, E., Ziv, E., \& Tang, H. (2002). Categorization of humans in biomedical research: Genes, race and disease. Genome Biology, 3, 2007.1-2007.12.

Rosenthal, M. B., Berndt, E. R., Donohue, J. M., Frank, R. G., \& Epstein, A. M. (2002). Promotion of prescription drugs to consumers. New England Journal of Medicine, 346, 498-505.

Roses, A. D. (2002). Pharmacogenetics place in modern medical science and practice. Life Sciences, 70, 1471-1480.

Rothman, D. J. (2001). The origins and consequences of patient autonomy: A 25-year retrospective. Health Care Analysis, 9, 255-264.

Sander, C. (2000). Genomic medicine and the future of health care. Science, 287, 1977-1978.

Sankar, P. \& Cho, M. (2003). Genetics: Toward a new vocabulary of human genetic variation. Science, 5597, 1337-1338.

Satel, S. (2001). Medicine's race problem. Policy Review, 110. Retrieved April 21, 2003, from http://www.policyreview.org/DEC01/satel.html

Schwartz, R. S. (2001). Racial profiling in medical research. New England Journal of Medicine, 344, 1392-1393.

Smedley B. D., Stith, A. Y., \& Nelson, A. R. (2002). Unequal treatment: Confronting racial and ethnic disparities in health care. Washington, DC: National Academy Press.

Spear B. B. \& Heath-Chiozzi, Huff, J. (2001). Clinical application of pharmacogenomics. Trends in Molecular Medicine, 7, 201-204.

Stewart, D.W. \& Shamdasani, P. N. (1990). Focus groups: Theory and practice. Newbury Park, CA: Sage.

Sumpradit, N., Fors, S. W., \& McCormick, L. (2002). Consumers' attitudes and behaviors toward prescription drug advertising. American Journal of Health Behavior, 26, 68-75.

Weber, W. W. (2001). The legacy of pharmacogenetics and potential applications. Mutation Research, 479, 1-18.

Wilson, J. F., Weale, M. E., Smith, A. C., Gratrix, F., Fletcher, B., Thomas, M. G., Bradman, N., \& Goldstein, D. B. (2001). Population genetic structure of variable drug response. Nature Genetics, 29, 265-269.

Woloshin, S., Schwartz, L. M., Tremmel, J., \& Welch, H. G. (2001). Direct-to-consumer advertisements for prescription drugs: What are Americans being sold? Lancet, 358, 1141-1146.

Wood, A. J. (2001). Racial differences in the response to drugs-Pointers to genetic differences. New England Journal of Medicine, 344, 1394-1396. 
Yancy, C. W., Fowler, M. B., Colucci, W. S., Gilbert, E. M., Bristow, M. R., Cohn, J. N., Lukas, M. A., Young, S. T., \& Packer, M. (2001). Race and the response to adrenergic blockade with carvedilol in patients with chronic heart failure. New England Journal of Medicine; 344, $1358-1365$.

Zachry, W. M., Shepherd, M. D., Hinich, M. J., Wilson, J. P., Brown, C. M., \& Lawson, K. A. (2002). Relationship between direct-to-consumer advertising and physician diagnosing and prescribing. American Journal of Health-System Pharmacy, 59, 42-49. 